\title{
A unique case of pronounced neurologic deficit from paraneoplastic syndrome that precedes appearance of mediastinal germinoma by two years
}

\author{
Anish Nanavati ${ }^{* 1}$, Jay Zeck², George Philips ${ }^{1}$, Najeebah A. Bade ${ }^{3}$ \\ ${ }^{1}$ Department of Hematology and Oncology, Georgetown University Hospital, Washington, DC, United States \\ ${ }^{2}$ Department of Pathology, Georgetown University Hospital, Washington, DC, United States \\ ${ }^{3}$ Department of Internal Medicine, Georgetown University Hospital, Washington, DC, United States
}

Received: August 5, 2015

DOI: $10.5430 /$ crcp.v3n1p6
Accepted: October 7, 2015

Online Published: October 19, 2015

\begin{abstract}
Paraneoplastic neurologic disorder may be the initial manifestation of a tumor, with the diagnosis of malignancy commonly found within six months of the onset of neurologic symptoms. This diagnosis is usually made on clinical grounds, as antineuronal antibodies are infrequently positive, though anti-Hu antibodies have been associated commonly with lung cancer. Typically, neurologic manifestations of germinomas include limbic and brainstem encephalitis in association with anti-Ma2 antibodies. To our knowledge, germinomas have not been associated with paraneoplastic cerebellar degeneration with anti-Hu antibody positivity. Here we report a case where neurologic deficits and anti-Hu positivity indicative of a paraneoplastic syndrome precedes the development of a mediastinal germinoma by two years.
\end{abstract}

Key Words: Anti-Hu antibodies, Anti-ANNA-1 antibodies, Paraneoplastic, Germinoma, Seminoma, Antineuronal

\section{INTRODUCTION}

Hu proteins function in the terminal differentiation of the neuron and the autoantibodies that cross-react with part of these proteins are known as anti-Hu antibodies (or anti-ANNA1 antibodies). ${ }^{[1]}$ High titers of anti-Hu antibodies indicate paraneoplastic syndrome of neurologic manifestation. Here we report a case where neurologic deficits and Anti-Hu positivity indicative of a paraneoplastic syndrome preceded the development of a mediastinal germinoma.

\section{CASE REPORT}

The patient is a 28 -year-old previously healthy left-handed Caucasian male whose initial presenting complaints in 2011 were hoarseness of voice and difficulty of depth perception while trying to catch baseballs. Right-sided vocal cord paralysis was initially noted and he subsequently developed rightsided hearing loss and sensorimotor deficits including weakness and numbness on the right side of his body. Evaluation with EEG, EMG, and brain MRI were all inconclusive with no etiology ascertained. Thereafter, his symptoms progressed with worsening gait imbalance. Standard laboratory workup was notable only for low Vitamin D levels and anti-Hu antibody positivity $(1: 30,720)$ with negative GQ1B ELISA titer. In light of the anti-Hu positivity, malignancy workup was performed, including CT chest and PET scan, which were unrevealing. A right superficial radial nerve biopsy showed

\footnotetext{
*Correspondence: Anish Nanavati, MD; Email: asnanavati@ gmail.com; Address: Department of Hematology and Oncology, Georgetown University
} Hospital, Washington, United States. 
no inflammatory cells or evidence of amyloid, but exhibited moderate loss of myelinated fibers indicative of severe axonal neuropathy. Prednisone was initiated and neurologic symptoms stabilized; steroid tapering began after six months of therapy, but recurrent symptoms of horizontal diplopia, gait imbalance, and loss of coordination of his right side ensued (see Table 1).

Table 1. Summary of imaging and lab evaluation

\begin{tabular}{llll}
\hline Imaging & $\mathbf{2 0 1 1}$ & $\mathbf{2 0 1 2}$ & $\mathbf{2 0 1 3}$ \\
\hline MRI brain & unrevealing & unrevealing & marked cerebellar volume loss, meningoencephalitis \\
PET/CT & negative & negative & hypermetabolic anterior mediastinal nodule \\
CT Scan C/A/P & negative & negative & right epididymal enlargement \\
Testicular U/S & negative & negative & \\
Labs & & & $\begin{array}{l}\text { positive } 1: 15,360 \\
\text { Anti-Hu Ab }\end{array}$ \\
Lumbar Puncture & positive 1:30,720 & & oligoclonal bands \\
\hline
\end{tabular}

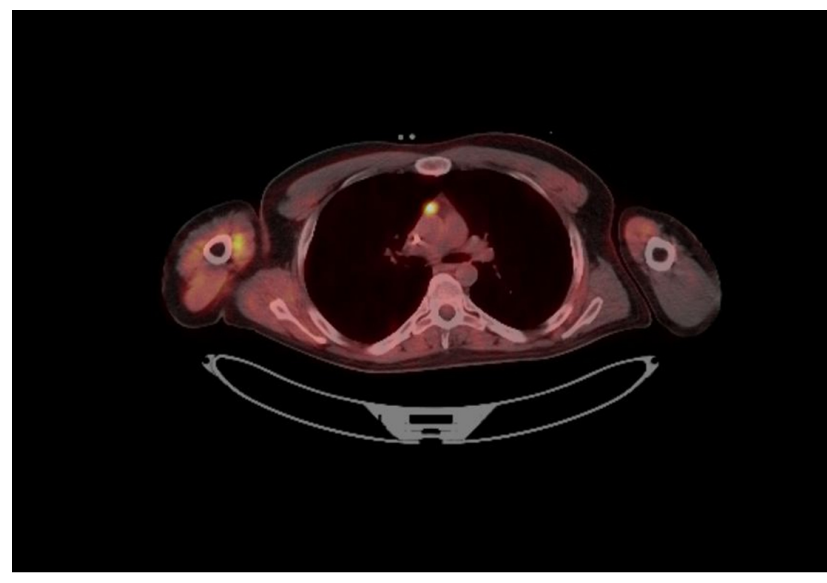

Figure 1. PET/CT 2013: Hypermetabolic anterior mediastinal soft tissue nodule $1.1 \mathrm{~cm} \times 1.1 \mathrm{~cm}$ (maximal SUV 10.4)

Further evaluation for suspected underlying malignancy including CT scans, testicular ultrasound, PET scan, and brain MRI were negative. Spinal fluid showed 6 oligoclonal bands. Intravenous immune globulin was given for 2 cycles with minimal improvement in symptoms. Two years later in May 2013, the patient developed left upper extremity, neck, and abdominal muscle weakness, as well as a tonic pupil on the left side. Azathioprine was initiated at a dose of $150 \mathrm{mg}$ orally daily with no significant improvement in symptoms.

Due to progressive symptoms, he was hospitalized to receive five days of plasmapheresis in July 2013 which led to transient improvement in symptoms for approximately one month. Several months later, an episode of generalized tonicclonic seizure with negative neuroimaging was treated with anticonvulsants and a repeat course of plasmapheresis. Physical exam at that time was notable for slurred speech, left tonically dilated pupil, dysconjugate gaze, nystagmus (vertical and horizontal), dysphonic voice, finger-to-nose dysmetria, wide-based spastic gait, left arm weakness, and reduced light touch, pinprick, and temperature sensation in right lower and upper extremities. Serum anti-Hu antibody was positive again at a titer of $1: 15,360$. MRI of the brain with contrast revealed cerebellar volume loss, along with abnormal signal enhancement of frontal lobe, suggestive of meningoencephalitis. Testicular ultrasound revealed right epididymal enlargement, which was felt to be a chronic process and unrelated. PET scan was performed, and demonstrated a $1.1 \mathrm{~cm} \times 1.1 \mathrm{~cm}$ hypermetabolic nodule in the anterior mediastinum with a maximum SUV of 10.4 (see Figure 1), which was not commented upon on his previous PET scan in 2012. Excisional biopsy of this mass by video-assisted thoracoscopic surgery and robotic thymectomy revealed mediastinal germinoma of seminoma-type arising within thymic tissue (see Figure 2, Figure 3), with focally positive CAM 5.2 and CD117 immunoreactivity. Placental Alkaline Phosphatase (PLAP) immunostaining was negative, while OCT4 staining was not evaluated. One superior mediastinal lymph node was negative for malignancy. LDH was mildly elevated at 350 (normal range 87-241), while serum AlphaFetoprotein (AFP) and Beta-Human Chorionic Gonadotropin (HCG) were both within normal limits.

Immunotherapy with the anti-CD20 monoclonal antibody, rituximab, was initiated while in the hospital, with objective but modest partial improvement in neurologic symptoms. Rituximab was dosed every 6 months thereafter, but as of May 2015, there had been no further neurologic response and no evidence of recurrence of this or other malignancy by body imaging including $\mathrm{CT}$ and PET scans.

\section{DiscuSSION}

Approximately $70 \%$ of patients with paraneoplastic neurologic disorder (PND) will present with neurological symp- 
toms as the first manifestation of the tumor. ${ }^{[2]}$ Of these patients, $75 \%$ will have an identified area of tumor on initial screening for malignancy. ${ }^{[3,4]}$

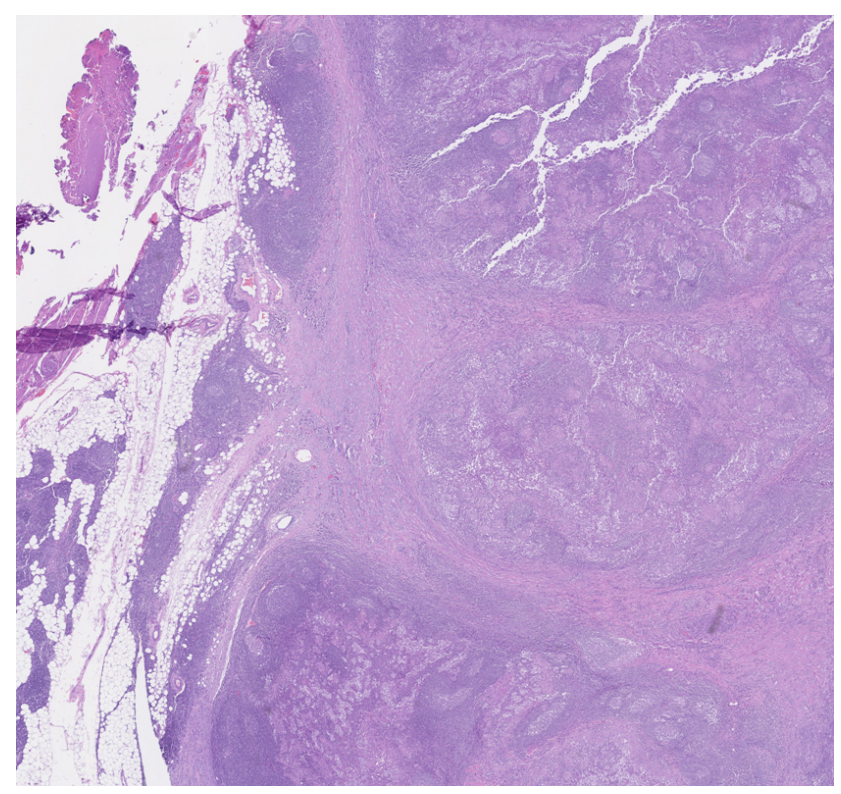

Figure 2. Low power view showing lobulated, densely cellular mass arising within thymic tissue (Courtesy of Dr. Jay Zeck. Georgetown University Hospital, Department of Pathology)

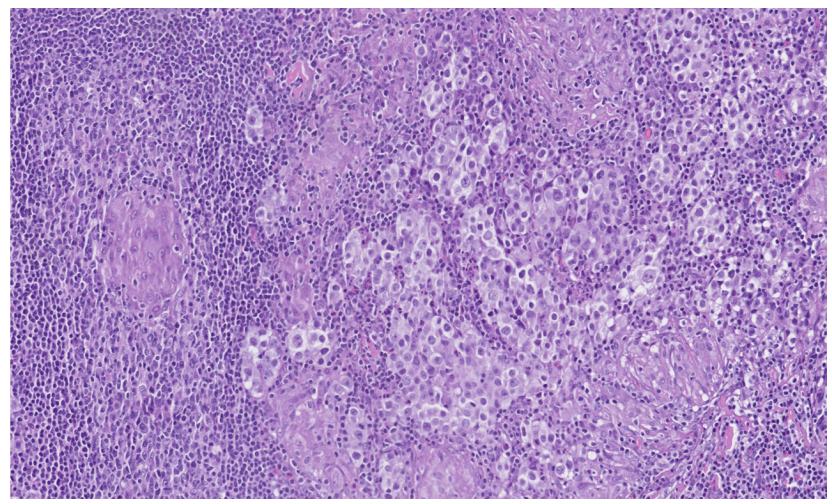

Figure 3. High power view showing large cells with abundant eosinophilic to clear cytoplasm and large nucleoli consistent with germinoma seen in a background of lymphoid cells. The malignant cells demonstrate diffuse immunoreactivity with CD117 and focal reactivity with cytokeratin CAM 5.2 (Courtesy of Dr. Jay Zeck. Georgetown University Hospital, Department of Pathology).

Paraneoplastic cerebellar degeneration (PCD) is a subacute, severe pancerebellar syndrome. Symptoms begin with mild neurologic deficits but proceed to gait instability followed by ataxia, diplopia, and dysphagia, ${ }^{[5-7]}$ similar to some of the symptoms present in our patient. Neuroimaging studies are frequently without significant abnormalities on initial study; however, cerebellar atrophy often becomes apparent on subsequent imaging studies. ${ }^{[8]}$ Hodgkin's disease, lung cancer, breast cancer, and ovarian cancer are most frequently associated with PCD. ${ }^{[9]}$

In a large study of 5,000 patients suspected to have PND based on clinical assessment, 137 patients were found with high titers of antineuronal antibodies. ${ }^{[9]}$ Of these patients, 90 were found to have anti-Hu positivity, 16 of whom had PCD and 46 had paraneoplastic sensory neuropathy (PSN). In the PCD patients, the mean age of diagnosis was 67 years (51-79 years). Thirteen of the patients with PCD presented at a median time of 6 months prior to the diagnosis of malignancy (range 0.9 to 18.4 months) while one patient had known malignancy upon diagnosis of PCD. In this study, 14 of the 16 patients with anti-Hu positivity were found to have lung cancer while two were without evidence of malignancy. Notably, patient outcomes were worse in patients with anti$\mathrm{Hu}$ positivity compared to patients with other identifiable antineuronal antibodies.

The most common paraneoplastic syndromes secondary to germinomas are limbic encephalitis and brainstem encephalitis. These syndromes are shown to most frequently be associated with Ma2 antibodies, which was interestingly absent in our patient. ${ }^{[10,11]}$ Rather, we detected elevated anti-Hu antibody levels, which is paradoxically most commonly associated with lung cancer, conclusively ruled out in our patient. Further, the association between germinomas and PCD has only rarely been reported, and in the cases reported, antibodies were either not evaluated or found to be negative. ${ }^{[12-16]}$ However, it should be noted that in our patient, sensorimotor and cranial nerve symptomatology suggests that the neurologic syndrome may have been distinct from an overlap syndrome (with brainstem involvement) in addition to PCD.

We show in our patient that high titer antineuronal antibodies and neurologic deficits can precede the appearance of malignancy by more than two years. For patients presenting with a suspected paraneoplastic neurologic disorder, the 2010 Taskforce recommends malignancy screening every 3 to 6 months after initial negative evaluation. ${ }^{[4]}$ In particular, health care providers must keep a broad differential in mind when considering potential underlying malignancies based upon the presence of antineuronal antibodies, as rare but previously undescribed associations may be found, as illustrated by our patient. 


\section{REFERENCES}

[1] Furneaux HF, Reich L, Posner JB. Autoantibody synthesis in the central nervous system of patients with paraneoplastic syndromes. Neurology. 1990; 40(7): 1085-91. PMid: 2356009. http://dx.d oi.org/10.1212/WNL.40.7.1085

[2] Posner JB. Neurologic complications of cancer. Philadelphia: FA Davis Company; 1995.

[3] Younes-Mhenni S, Janier MF, Cinotti L, et al. FDG-PET improves tumour detection in patients with paraneoplastic neurologic syndromes. Brain. 2004; 127: 2331-38. PMid: 15361417. http: //dx.doi.org/10.1093/brain/awh247

[4] Linke R, Schroeder M, Helmberger T, et al. Antibody-positive paraneoplastic neurologic syndromes: value of CT and PET for tumor diagnosis. Neurology. 2004; 63: 282-6. PMid: 1527762. http: //dx.doi.org/10.1212/01. WNL.0000129983.06983.4E

[5] Peterson K, Rosenblum MK, Kotanides H, et al. Paraneoplastic cerebellar degeneration. I. A clinical analysis of 55 anti-Yo antibody positive patients. Neurology. 1992; 42: 1931-7. PMid: 1407575. http://dx.doi.org/10.1212/WNL.42.10.1931

[6] Rosenfeld MR, Eichen JG, Wade DF, et al. Molecular and clinical diversity in paraneoplastic immunity to Ma proteins. Ann Neurol. 2001; 50: 339-48. PMid: 11558790. http://dx.doi.org/10.10 02/ana. 1288

[7] Yu Z, Kryzer TJ, Griesmann GE, et al. CRMP-5 neuronal autoantibody: marker of lung cancer and thymoma-related autoimmunity. Ann Neurol. 2001; 49: 146-54. http://dx.doi.org/10.1002/1 531-8249(20010201) 49:2<146: : AID-ANA34>3.0.CO;2-E

[8] de Andres C, Esquivel SA, de Villoria JG, et al. Unusual magnetic resonance imaging and cerebrospinal fluid findings in paraneoplastic cerebellar degeneration: a sequential study. J Neurol
Neurosurg Psychiatry. 2006; 77: 562-63. PMid: 16543544. http: //dx.doi.org/10.1136/jnnp.2005.073379

[9] Shams'ili S, Grefkens J, de Leeuw B, et al. Paraneoplastic cerebellar degeneration associated with antineuronal antibodies: analysis of 50 patients. Brain. 2003; 126: 1409-18. PMid: 12764061. http://dx.doi.org/10.1093/brain/awg133

[10] Dalmau J, Graus F, Villarejo A, et al. Clinical analysis of anti-Ma2associated encephalitis Brain. 2004; 127: 1831-44. PMid: 15215214 http://dx.doi.org/10.1093/brain/awh203

[11] Mathew RM, Vandenberghe R, Garcia-Merino A, et al. Orchiectomy for suspected microscopic tumor in patients with anti-Ma2-associated encephalitis. Neurology. 2007; 68: 900-5. PMid: 17151337. http: //dx.doi.org/10.1212/01.wnl.0000252379.81933.80

[12] Dalmau J, Rosenfeld MR. Paraneoplastic syndromes of the CNS. Lancet Neurol. 2008; 7: 327-40. http://dx.doi.org/10.1016 /S1474-4422(08)70060-7

[13] Yamada M, Okeda R, Chen W, et al. Cortical cerebellar degeneration with testicular neoplasm. Acta Neuropathol. 1985; 66: 170-2. PMid: 2990143. http://dx.doi.org/10.1007/BF00688695

[14] Kaluza J, Slowinski J, Bujny T, et al. Paraneoplastic syndrome simulating encephalitis in the course of testicular seminoma. Folia Neuropathol. 1997; 35: 24-8. PMid: 9161097.

[15] van de Warrenburg BP, Rodriguez-Justo M, Vella NR, et al. Paraneoplastic cerebellar ataxia due to burnt-out testicular germ cell tumour? Eur Neurol. 2007; 57: 178-81. PMid: 17218768. http: //dx.doi.org/10.1159/000098472

[16] Sola-Valls N, Gaba L, Munoz E, et al. Paraneoplastic cerebellar degeneration associated with thymic germinoma. J Neurol Sci. 2012; 320: 153-5. PMid: 22795387. http://dx.doi.org/10.1016/j .jns.2012.06.021 